\title{
Analysis of Risk in Supply Chain Information Sharing and the Countermeasures
}

\author{
Feng Wang \\ School of Health Information Technology and Management, Shanghai University of Medicine \& Health Sciences, \\ Shanghai, China \\ E-mail: Wangf@sumhs.edu.cn
}

\begin{abstract}
The supply chain is called the sharp weapon of the business enterprise competition by the industry in 21 centuries. This function of the supply chain is decided by the valid share of information between the member's business enterprises. Because all of the supply chain member's business enterprises are a independent economic individual that to pursue the benefits maximize, and the benefits allotment mechanism is not exert fair, reasonable of place in the current supply chain's, the benefits encourages mechanism and the risk guard against mechanism are not completely built up or sound, risk problem in the information share will take place. This text firstly analyzed the risk problem in the information share, and as to analyze the reason, and then put forward some counter plan measure against the occurrence of risk.
\end{abstract}

\section{Keywords-Supply chain; Information share; Risk; Counter plan}

\section{INTRODUCTION}

In the 21th century, the competition of enterprises around the world has shifted from between enterprises or between products to between supply chains. The coordination of supply chain operation is based on the high-class transmitting and sharing of information among the node companies. Sharing of information could enable the chain companies to make a better arrangement of production and inventory distribution plan. At the same time, it promotes the mutual trust among the cooperation companies in order to have a quicker respond to market changes. Therefore, information sharing is the basis to realize supply chain management. However, there are huge risks in sharing information. Without precaution, it would fail to provide high-quality, low-cost and personalized product or service to customer in time with the integrative advantage. So, the following topics will be discussed, which are: what are the exact risks in supply chain information sharing, the reason of it and the ways to prevent them.

\section{ANALYSIS OF THE RISK AND ITS CAUSES IN SUPPLY CHAIN INFORMATION SHARING}

1) For the sake of costs, some companies might not share all the information with node companies. The level of information sharing would be low when only part of the information has been shared.

To achieve information sharing, it requires a solid IT foundation, which would cost the companies a large investment in purchasing hardware and building information managing system. In addition, the training of relevant personnel and necessary improvement of process, etc., would also bring high costs. The higher the level of information sharing is, the higher the cost will be. Therefore, decision maker of the company will have to weigh between the costs and the profits information sharing brings to determine the best degree of sharing. This might cause the phenomenon that the supply chain information is not completely shared.

2) Some supply chain companies provide fake information to maximize their own profits.

It has become a consensus that information sharing must be implemented to improve the efficiency and competitiveness of the supply chain. However, the consensus does not equal to the action that every company make effort to achieve high information sharing. The reason is that enterprises sharing the information in supply chain are different economic individuals who both cooperate and compete with each other in a "principal-agent" relationship. Under the circumstances that the current benefit allocation mechanism has not been perfectly established, the prisoner's dilemma caused by interest game is inevitable. To pursue maximum self-profit, enterprise might make choices that are best to its individual instead of those best to the group.

3) Company's business secrets would leak from unscrupulous members after information sharing due to lack of effective mechanism of supervision and control.

Every enterprise in the supply chain has its own core business secrets, such as the purchase channels of raw materials, prices, composition of items, manufacturing process, technology, sales channels and services, which is the core competence against opponents. These secrets will enter a "public domain" after information sharing and all the upstream and downstream companies will have access to these information. Since the supply chain has a network-chain structure that, for the core enterprise, one kind of product could have several suppliers to provide highly replaceable products. On the one hand, any supplier would wish to get hold of the comprehensive information of one particular product including the sales performance, sales channels, service means and even manufacturing process and technology of the similar products of its competitors, to develop an appropriate strategy. On the other hand, all the different suppliers are competitors to each other. Their competition will get much more intense because of the market power's transfer to the buyer and globalization. So the suppliers want to seize information of their competitors and, at the same time, protect theirs from them. Now that the information is disclosed on the supply chain, the secrets could possibly be betrayed by the immoral act of core enterprise. Although, theoretically, the target supplier is not necessarily on the 
same supply chain, it might be on the same network. Even if the core enterprise does not do this, the odd of leaking is still high because all the upstream and downstream companies can see the information as well. The competitive advantages depending on these secrets will lose ever since they are leaked.

\section{RISK COUNTERMEASURES OF INFORMATION SHARING IN SUPPLY CHAIN}

1) Scientific and rational choice of supply chain partners

The quality of partner is the core issue that directly related to whether there would be a risk in information sharing. In selecting partners, one is not only to consider partners with the core resources and their matching, enterprise culture, management methods, organizational structure, technical standards, software and hardware, the solubility of strategic objectives, inter organizational coordination, etc., more importantly, is to examine whether partners have high business reputation, credit level, corporate ethics, and team spirit. When choosing supply chain partners, a minimum credit threshold should be set, and only those enterprises, which are above the minimum credit threshold.

\section{2) Establish reasonable benefit distribution mechanism}

Supply chain is a "multiple interest group" consisting of several independent corporate entities without any affiliation. Its operation is based on the target that all the companies participating can get reasonable earnings. When the overall profit of the supply chain group is set, the profit allocation of each company is a shift relationship. In this case, the "win-win" principle must be used in the operation of supply chain. It must guarantee that every partner companies in the supply chain is profitable and, at the same time, receives equal to their efforts. This is how the trusted cooperating relationship of the supply chain partners is build and maintained. Therefore, establishing a reasonable benefit distribution mechanism is the primary condition to prevent inadequate information sharing and delivering fake information in the supply chain.

To this end, an incentive mechanism should be built, which could promote the cooperation and trust between partners. The profit they get from benefit distribution should differ according to the link they are responsible for, the how much they invest and the risk they take. At the same time, it could encourage the members' passion of working and investing when they are guaranteed that the more they work, the more they get. On the other hand, a motivation and compensation mechanism should also be built. Those companies who suffered loss to make best earnings of the group should be compensated so that they are willing to make effort for the target of the whole supply chain with their own resources. The compensation should come from the node companies who have made greater profits from the supply chain system. This requires an interest coordinating mechanism in the supply chain system.

3) Establish reasonable interest incentive mechanism
The supply chain is a strategic alliance of interests. To realize high information sharing and avoid varies of information crisis among alliance members, reasonable interest incentive mechanism should be established besides the benefit distribution mechanism so that the enthusiasm of member companies are aroused. There are following kinds of interest incentive:

First, the price incentive. As stated in the front, supply chain members are independent economic individuals. They will try to pursue the maximization of interests in the supply chain profit distribution. The primary cause of partial information sharing and fake information or delay is interest. The profit distribution among the enterprises in the supply chain is mainly reflected in price. It contains the distribution of each enterprise of the supply chain profits, extra earnings from supply chain optimization and the balance of the loss among all the enterprises. The extra earning or loss of supply chain optimization is often taken by the corresponding enterprise. For example, the manufacturer can implement price motivation to suppliers to reduce inventory while ensure the production uninterrupted. The suppliers will cooperate actively due to the interest they get.

Second, order incentives. Under the supply chain management, manufacturer could face multiple suppliers with products of the same quality. Thus, the internal competing mechanism is formed. The manufacturer would increases orders to stimulate if the supplier could fully share information, keep the business secrets and perform well on product quality and delivery term. Thus the risk of information will not appear since the supplier will obey the rules with more orders from the manufacturer. More orders means more profits.

Third, reputation incentives. The reputation of the enterprise is its intangible capital. It is the credit and fame obtained through its business operations from society. So, the reputation incentive is a useful way to raise the consciousness of high information sharing, prevent fake information and business secrets leaking of the supply chain members.Specifically speaking,it is to establish a subsystem in the supply chain managing system to evaluate the credit point of each member during a specific term. Rank the companies with a set evaluation criterion and publicize through the system or the media if condition permit. These could help the good enterprises to earn reputation and more market chances while penalize those misconduct enterprises that are selfish and disobey rules of market economy.

4) Sign information sharing agreement

The information sharing agreement is an effective managing tool. It plays an important role in standardizing and constraining information sharing action of member enterprises, insuring high-level information sharing and preventing information leaking. The information sharing agreement should cover five main aspects. First, member enterprises promise to fully share information that help supply chain to work effectively without hiding and holding back. Second, member enterprises promise not to deliver 
fake or delayed information. Third, member enterprises undertake the obligation confidentiality and never betray the business secrets of other members. Fourth, rewards should be given to those enterprises that keep the promises, perform nicely and made great contribution to the whole benefit of the supply chain. Fifth, warnings should be given to those enterprises that fail to keep the promises and perform poorly. If the circumstances are minor, these enterprises should be given a time limit to correct themselves or they will be considered to eliminated. If their behavior has caused damaged to other members, they should offer necessary reparation or compensation. If the circumstances are serious, they will be investigated for legal responsibility. With this agreement, the sense of responsibility of the member enterprises will enhance. They will definitely keep the promise to realize full information sharing for both the group advantage and self development they could get from the supply chain managing system. Even when a member enterprise wants to break it, they will consider over and over between gain and loss. This makes it an objective restriction.

5) Comprehensively use a variety of models information sharing

Many enterprises worry that the communal trading system may damage the cooperating relationship with their important business partners and reveal their business secrets so that they lose the advantages. To avoid the pressure of total information transparency, it could the provider to build the mapping table and go through the third party platform packed and none-stop. It would seem like a private trading system for every member on the platform.

6) Improve overall supply chain monitoring and evaluation mechanism

Currently, there are monitoring and evaluation mechanisms in the supply chain system, but those are mostly based on the traditional organization structure. It often focus only on efficiency of a single department or enterprise while ignores the characteristic of the whole supply chain, which are beyond functional boundaries and organizational boundaries. Therefore, the only method can achieve the main goal of profit-maximizing and maintain the relationship of sharing information is to establish, improve the overall monitoring mechanism of supply chain, evaluate the sharing information, identify the problems in regular and make some adjustment.

7) Establish a set of sharing information and risk forewarning evaluation index system

Most risks of information sharing in supply chain are highly predictable, thus that it is necessary to establish a set of "early warning" index system and set up "risk threshold". Through continuous information collection, process and feedback to monitor the supply chain operating state. As more than one indicators deviate normal level are discovered, the system will sending early warning signals to avoid enterprise further losses.

Overall, the supply chain is a complex made up of several enterprises, but the moral standards and integrity of each enterprise is not at the same level, and the common goal of them is profit maximizing. Thus, the risk will happen in information sharing, which is an objective reality. As long as the member enterprises of the supply chain truly establish a strategic cooperating relationship, implement a fare and reasonable interest incentive mechanism, and establish and improve the incentive motivation mechanism and risk prevention mechanism, the whole interest maximization of the supply chain could be achieved while the risks in information sharing could be prevented effectively.

\section{REFERENCES}

[1] A. Foul, L. Tad, R, "Hedjar. Adaptive control of inventory systems with unknown deterioration rate", Journal of King Saud University Science, vol.3, 2011

[2] Yiyo Kuo, Chi-Chang Wang, "A variable neighborhood search for the multi-depot vehicle routing problem with loading cost", Expert Systems With Applications, vol.8, 2012.

[3] Van der Sijs H, van Gelder T, Vulto A, et. al., "Understanding handling of drug safety alerts: a simulation study", International Journal of Medical Informatics, 2010. 